\title{
Assessing companion dog behaviour in a social setting
}

\author{
Lina S V Roth and Per Jensen
}

\section{Linköping University Post Print}

\section{Tweet}

N.B.: When citing this work, cite the original article.

Original Publication:

Lina S V Roth and Per Jensen, Assessing companion dog behaviour in a social setting, 2015, Journal of Veterinary Behavior: Clinical Applications and Research, (10), 4, 315-323.

http://dx.doi.org/10.1016/j.jveb.2015.04.003

Copyright: Elsevier

http://www.elsevier.com/

Postprint available at: Linköping University Electronic Press

http://urn.kb.se/resolve?urn=urn:nbn:se:liu:diva-118692 


\section{Assessing companion dog behaviour in a social setting}

Lina S V Roth* \& Per Jensen

IFM Biology, AVIAN Behaviour Genomics and Physiology Group. 58183

Linköping University, Sweden. *Corresponding author: linaroth@ifm.liu.se, Phone:

$+4613282611$ 


\section{Abstract}

2 There is a growing and important need for large-scale characterisation of dog

3 behaviour, for example to conduct genetic analyses or to assess welfare. An extensive

4 number of standardised tests and questionnaires are used for this, but few focus on the

5 normal behaviour in situations which are frequently encountered in the everyday life

6 of companion dogs. The aim of this study was to develop and validate a fast, but

7 standardised method to characterise behavioural variation in pet dogs, based on a brief

8 observation in a situation often encountered by many dogs, namely during training

9 classes. The spontaneous behaviour of dogs was video-recorded during 3 minutes in a

10 standardised setting, while their owners were occupied filling in a short questionnaire,

11 and during 30 seconds of walking on leash. Behaviours, including contact seeking

12 behaviour with both the owner, a stranger and other dogs, together with general

13 activity and interaction with a novel object were later analysed and further processed

14 in two separate Principal Component Analyses (PCA). The PCs from the two test

15 parts correlated significantly with each other and aspects of both home and test

16 environment influenced several components in both PCAs. Age and sex also showed

17 significant effects on test outcome, e.g. age affected how social and explorative the

18 dog was and females jumped more on their owner, whilst males pulled the leash more.

19 In addition, dogs that were perceived as cooperative by their owner, looked more at

20 their owner and pulled the leash less. In conclusion, this simple test captures essential

21 parts of the normal, everyday behaviour profile of dogs, such as owner- and dog-

22 directed social behaviour, which are not usually measured in the commonly used test

23 batteries for dogs.

25 Keywords: companion dog, behaviour, method, assessment, social, exploration 


\section{Introduction}

27 Dogs (Canis familiaris) have been domesticated for thousands of years $[1,2]$ and their importance in today's society ranges from companions to workers, including examples such as guide dogs and dogs used by the police, the armed forces and customs. This has sparked a large interest in research into dog behaviour, as a means to understand dog welfare and performance, as well as dog-human relationships, and since dogs are increasingly used for behaviour genetics studies [3,4]. Many such studies require extensive phenotyping of large numbers of individuals, which calls for standardised, high-throughput test batteries. Preferably, such tests should capture essential aspects of the behaviour in situations where the dog is as relaxed as possible. One problem is that observations in the home environment are time-consuming and incompatible with high throughput, whereas standardised test situations may not be representative of the normal life of most companion dogs.

In Sweden, as in many western countries, most companion dogs participate in training

41 classes such as puppy training classes, various obedience training, agility or show handling at least some time during their lifetime. These courses therefore offer a promising possibility to reach a large number of companion dogs in a limited time, and to record their behaviour while they are in a setting which resembles their everyday life situation i.e. when they are together with their owners in an environment with less familiar dogs and humans.

48 Previously, a number of test batteries have emerged with the purpose of determining individual dog behaviour [5]. Most standardised tests are performed in an environment, which is unfamiliar to the dog and often include both sudden and novel 
51 stimuli [5-7], to a large extent measuring the behaviour during stress and fear. For example, the Swedish armed forces select dogs for training and breeding based on

53 performance in a battery of more or less fear-inducing test situations [8-10]. The dog

54 mentality assessment (DMA), and the new version Behavioural and Personality

55 description for Dogs (BPD) in Sweden, aim at describing the behaviour and

56 temperament of mainly companion dogs. Their subtests score the dog's behaviour

57 when he/she is approached by different social and non-social fear-inducing stimuli, in

58 a play situation, in a passive situation while stimulating chasing and in BPD also in a

59 problem solving task $[11,12]$. These tests are popular among dog owners, generate

60 large data sets, and can be valuable tools for enhancing our understanding of

61 behavioural differences, e.g. between breeds [13]. However, crucially, the tests fail to measure some of the most important aspects of dog behaviour in present society: the

63 relationship to the owners and the behaviour towards other dogs. Perceived

64 dysfunction in any of these aspects of dog behaviour cause large welfare problems to

65 both owners and dogs, and are important causes of early euthanasia of dogs in the

66 western world $[14,15]$. Furthermore, the tests rely on subjective scoring of behaviour,

67 based on the impression gained by a test leader who usually lacks formal ethological

68 training. Hence, there is an urgent need for ethologically rigorous, standardised

69 behavioural tests, which capture a broad range of dog behaviour in a situation where a

70 minimum of stress and fear is induced, and where behaviour can be scored using

71 quantitative ethological methods.

73 Only a few studies have been performed in an environment familiar to the dog or in 74 situations that are more or less normal to the individual dog [5]. For example, a recent 75 study video-recorded owners and their dogs under natural circumstances during walks 
in both city centres and in green areas [16], but this study did not attempt to evaluate the behaviour or temperament of the dogs in a broader context. The small number of studies performed in the natural environment of dogs is probably due to the difficulty in standardising and evaluating these kinds of tests. Still, being able to faithfully record the normal behaviour repertoire is essential for a full and rich understanding of

81 behaviour variation. Social interaction, exploratory behaviour and general activity in everyday life should be valuable behavioural components when comparing breeds, age classes and sexes, and when relating this to, e.g., earlier experiences of the dogs.

Another common approach is to use questionnaires to collect owners' subjective impressions about their dogs $[17,18]$. The owners' knowledge about their dogs can reduce behavioural noise due to daily or seasonal variations, which cannot be accounted for in a single behavioural test. Even though questionnaires are to some extent subjective, they are still regarded valuable complements to behavioural studies $[11,19,20]$.

Facing the limitations of current test methods, the aim of the present study was to develop and evaluate a simple, fast and standardised behavioural assay for companion

94 dogs which can be applied when they are kept together with their owners and other 95 dogs. The test should be possible to apply on large numbers of dogs with limited time expenditure, while still providing rigorous, quantitative ethological data. 
100 Recordings were taken immediately before ordinary dog training classes for

101 companion dogs in the cities of Linköping and Vimmerby, in South-Eastern Sweden.

102 We visited obedience courses, puppy courses, freestyle courses, agility and tracking

103 courses (see supplementary table 1 for a complete list). In total we visited four

104 outdoor environments, which all were open fields looking similar to each other (fig.

105 1A) except for the tracking course that was visited on a forest road. The indoor

106 courses were performed either on the second floor of a barn with fitted carpet and

107 with the total measurements of approximately 12 x $30 \mathrm{~m}$ (fig. 1B; we only used half

108 of the length) or in a smaller dog training room with fitted carpet and approximately 5

$109 \times 10 \mathrm{~m}$.

110

111 It was voluntary for the owners to be included in this study and they all gave their

112 written consent. All study subjects $(\mathrm{N}=85)$ were privately owned dogs including 33

113 females and 52 male dogs with an average age of 31 months (SEM=2.8; see

114 supplementary table 1 for breed and individual details). Information about the home

115 situation, the course experience of the dog, the dog training experience of the owner

116 and the owner's own subjective scoring of some behavioural parameters were

117 obtained by a questionnaire.

119 Testing procedure

120 The general aim of the test was to video-record the behaviour of dogs during a

121 standardised procedure which was likely to be perceived by the dog to be as normal as

122 possible. Additionally, we aimed for a situation where the dogs could choose to

123 behave freely without restrictions from their owners. These videos were then

124 subjected to a detailed ethological analysis. The owners were informed about the 
125 procedure, without revealing the methods or any details of the intended analysis.

126 During the entire test, the behaviour of all dogs in that test session was video-recorded

127 using two HD camcorder (Canon Legria HF M52), positioned on a tripod

128 approximately 4-8 $\mathrm{m}$ from the dogs.

129

130 The test was split into two different parts, in which the owners were not paying

131 attention to the dogs during part one, while they did interact loosely during the second

132 part. This procedure was intended to allow calculations of the consistency of the

133 behavioural assessment over two different situations. By performing the two different

134 assessments shortly after each other, two different data sets could be obtained from

135 each dog without having to invite the dog owners to participate on different occasions.

136 Hence, all dogs participated in both situations. Still, behavioural data from a few dogs

137 were excluded since their owners paid them so much attention during the first part of

138 the test (> 3 owner contacts with the dog) that the dogs were not regarded to be

139 representative.

141 Part one

142 The owners were asked to walk up with their dogs on leash and each stand behind an

143 orange plastic cone ( $4 \mathrm{~cm}$ high and $19 \mathrm{~cm}$ in diameter) with an extended black and

144 white paper roll. This resembles the situation most dogs encounter during a training

145 class while the instructor informs owners, and in this test the cones served as a novel

146 object for the dog as well as a position marker (fig. 1). The paper roll was $21 \mathrm{~cm}$ high

147 (4 $\mathrm{cm}$ within the cone), rigid and did not move or generate noise when affected by

148 wind, and, in spite of it being a novel object, should therefore have been minimally 
149 fearful for the dogs. The distance between the cones was $2.5 \mathrm{~m}$ and the number of 150 dogs tested at the same time was between two and eight.

152 To distract dog owners from affecting their dogs during video-recording, they were

153 asked to fill out a questionnaire while standing at the cone, and the intention was to

154 create a situation where the dog could act on his/her own initiative, without any 155 obvious interference from the owner. Hence, the questionnaire did not primarily serve 156 to gather representative information, but mainly to occupy the owners for a few 157 minutes, but nevertheless some fundamental data about the background of the dogs 158 could be collected in this way (see below). In addition, during the whole procedure, 159 the owners were asked not to give any command or treat to their dogs and concentrate 160 on filling out the questionnaire.

162 On three occasions during part one, the reactions of the dogs towards an approaching 163 unknown person were recorded. This was obtained by the test leader (acting as a 164 stranger in this test) approaching each of the owners and their dogs while handing out 165 the questionnaires. During a second round, pencils were handed out and later, after a 166 couple of minutes, the test leader collected all completed questionnaires, approaching 167 each owner and dog a third time.

169 For part one, three minutes of the recorded video was later analysed and this first part 170 of the test assessed the behaviour of the dogs towards the stranger, the novel object, 171 the owner and other dogs, and the general activities of the dogs, while the owners 172 were occupied filling out the questionnaires. 


\section{Part two}

175 Part two took place subsequent to part one, after the collection of the surveys. For this 176 part, the owners were asked to walk their dogs on a loose leash in a big circle around 177 all orange plastic cones and during this time, behaviour was recorded during $30 \mathrm{~s}$.

\section{Questionnaire}

180 As mentioned previously, the purpose of the questionnaire was to keep the owners 181 occupied and not attentive to the dogs. However, some basic information about the 182 dogs was possible to obtain in this way. The survey consisted of eight questions about

183 the dog; what sex, breed and age the dog was; whether the dog was living in an 184 apartment or in a house; whether the dog was living alone or with other dogs; if the 185 dog had been attending training classes before or not; if this was the first training 186 class for the owner or whether he/she had attended several courses before or if he/she 187 where training and competing regularly; and lastly about the aim of participating in 188 this training class. In addition the survey included short general statements where the 189 owner was asked to rate his/her dog on a scale 1-5 for; how happy the dog is to see 190 humans; how happy the dog is to see other dogs; how curious/unafraid the dog is; 191 how playful the dog is; how aggressive or threatful the dog is towards humans; how 192 aggressive or threatful the dog is towards other dogs; how cooperative their dog is and

193 finally how stressed they generally perceive their own dog to be. These statements 194 were deliberately kept subjective, since their purpose was only to obtain the owners' 195 personal impressions.

\section{Analysis}


From the two test parts, the frequency of all behaviours of interest were recorded from video-recordings according to a pre-determined ethogram (Table 1). The recordings

200 from part one started from the time that the dog was less than one meter from the 201 plastic cone, and proceeded for $3 \mathrm{~min}$. From the second part of the test when the dogs 202 were being walked around the cones, an additional 30 seconds were analysed. All 203 behaviours were scored while watching the videos in iMovie '11 (version 9.0.9; 204 Apple Inc.) using Excel 2011 (Microsoft) with 1/0 interval sampling every five seconds, Hence, for each $5 \mathrm{sec}$ interval a behaviour item could score maximum 1 even though the behaviour was performed several time, which thereby generate a minimum

207 frequency of each behaviour over 3 minutes (part1) and $30 \mathrm{sec}$ (part2). We will

208 henceforth refer to this as frequency. Each video was viewed repeatedly scoring 209 behaviour from one dog at the time. One trained person scored the behaviour for all 210 dogs. One additional person scored seven main behaviour items for eight of the dogs

211 and an inter-observer reliability test showed high correlation (Spearman's correlation; $212 \mathrm{r}=0.98 ; p<0.001)$

\section{Statistics}

215 A principal component analysis (PCA) without rotation of PCs was performed both 216 for behaviours recorded from the first part of the study (the three minutes when the 217 dog was situated by the cone) (Table 2; $N=78$; Bartlett's sphericity test, $\chi^{2}=1249.92$, $218 \mathrm{df}=231, p<0.001 ; \mathrm{KMO}=0.605)$ and the second part (30 seconds of walking) (Table $2193 ; \mathrm{N}=78$; Bartlett's sphericity test, $\chi^{2}=261.72, \mathrm{df}=66, p<0.001 ; \mathrm{KMO}=0.659$ ). For 220 each of the two PCAs, individual component scores were calculated for each of the 221 dogs, and correlations between component scores from the two test parts were calculated with Pearson's correlation analysis. The effects of questionnaire item 
responses on PC scores were analysed with a one-way ANOVA. Separate behavioural

224 items were analysed with non-parametric methods. All statistical analyses were performed in IBM SPSS Statistics 22.

\section{Results}

\section{Part one}

230 The PCA of the recorded behaviours from part one resulted in seven components with

231 Eigenvalues above one. Based on the scree plot we chose to focus on the first five 232 with Eigenvalues above 1.34, which explained $65 \%$ of the variation. The first 233 component was labelled Social and had high loadings for contact behaviours towards 234 both other dogs and the stranger (Table 2). The second component was named 235 Explorative and was mainly related to interest in the novel object, activity and sniffing the ground. The third component was called Curious and still and had high loadings

237 for behaviours such as lie down, looking at owner and interest in novel object. The 238 fourth component, labelled Contact, relates mainly to the behaviour looking at the 239 owner but also looking at the stranger and, lastly, the fifth component that was named 240 Restless, had high loadings for shaking and yawning behaviours. Young dogs ( $\leq 2$ years; $\mathrm{N}=41$ ) had higher PC scores for both component 1 (Social; fig.

$2432 \mathrm{~A}$ ) and component 2 (Explorative; fig. 2B) than older dogs ( $>2$ years; $N=37$; one244 way ANOVA; $\mathrm{F}(1,76)=6.6$ and 5.2 respectively; $p<0.05)$. In addition, the total 245 number of dogs in the household had a significant effect on component 2 246 (Explorative; fig. 2C) and 5 (Restless; fig. 2D) where dogs living as the only dog in 247 the household $(\mathrm{N}=49)$ had higher scores than those living with other dogs $(\mathrm{N}=27$; oneway ANOVA; $\mathrm{F}(1,74)=6.1$ and 5.3 respectively; $p<0.05)$. 
250 Dogs attending outdoor courses $(\mathrm{N}=51)$ showed higher loadings for component 1

251 (Social; fig. 2E) than dogs on indoors courses $(\mathrm{N}=27$; one-way ANOVA; $\mathrm{F}(1,76)=6.3$;

$252 p<0.05$ ) and the latter also had higher values for component 5 (Restless; fig. 2F; one-

253 way ANOVA; $\mathrm{F}(1,76)=9.2 ; p<0.01)$.

255 However, comparing the results between the different outdoor environments revealed

256 that the tracking course (that was visited in the forest) showed significantly higher

257 loadings in component 1 (Social) than all other outdoor courses performed in open

258 fields (one-way ANOVA; F(3,49)=7.8; $p<0.001$ ). Nevertheless, when the five dogs

259 from the tracking course were excluded the component 1 (Social) still showed higher

260 loadings for outdoor courses compared to indoor courses (one-way ANOVA; F(1,

$26173)=4.0 ; p<0.05$.). No differences were found when comparing results between two

262 different indoor environments.

264 Dividing the dogs depending on whether it was the first course day $(\mathrm{N}=39)$ or not $265(\mathrm{~N}=39)$ revealed dogs on the first course day to have lower scores for component 4

266 (Contact; fig. 2G; one-way ANOVA; F(1,76)=10.3; $p<0.01$ ).

268 Part two

269 The Principal component analysis of behaviours from part two resulted in four

270 components with Eigenvalues over one, explaining $65 \%$ of the variation (Table 3 ).

271 The first component was labelled Social and had high PC loadings for all recorded

272 behaviours towards other dogs. The second component was named Explorative and

273 relates mainly to interest in the novel object, sniffing the ground and pulling the leash. 
274 The third component relates to both interest in the novel object and contact behaviour

275 with the owner and was named Curious \& contact. Finally, the forth component,

276 labelled Restless, had high loadings for shaking behaviour and to some extent also

277 jumping on owner. Note that there were fewer behaviour items scored during part two

278 compared to part one since we did not have a stranger situation (which heavily

279 influenced PC 1 in part one, labelled Social) and since the dogs always were walking

280 during part two. However, the essential behaviour items in the corresponding

281 components were still very similar.

282

283 Unsurprisingly, age had a significant effect on PC 2 (Explorative; fig. 3A) where

284 young dogs $(\leq 2$ years; $N=41)$ had higher scores than older dogs ( $>2$ years; $N=37$; one-

285 way ANOVA; $\mathrm{F}(1,76)=8.0 ; p<0.01)$. Furthermore, the dog's home environment

286 influenced the behaviour of the dog since access to a garden significantly affected PC

2872 (Explorative; fig. 3B). Dogs living in an apartment without direct garden access

$288(\mathrm{~N}=34)$ showed higher scores than those living in a house having direct access to

289 garden $(\mathrm{N}=44$; one-way ANOVA; $\mathrm{F}(1,76)=4.6 ; p<0.05)$. In addition, our results

290 suggest that the test environment could affect behaviour since dogs on outdoors

291 courses $(\mathrm{N}=51)$ had higher loadings for both component 1 (Social; fig. 3C) and

292 component 2 (Explorative; fig. 3D) than dogs on indoors courses ( $\mathrm{N}=27$; one-way

293 ANOVA; $\mathrm{F}(1,76)=6.1$ and 7.1 respectively; $p<0.05$ and $p<0.01$ respectively).

295 Comparing the results from the different outdoor environments showed that the

296 loadings from component 2 (Explorative) differed between the two main outdoors

297 sites on open fields (one-way ANOVA; $\mathrm{F}(3,49)=4.0 ; p<0.05$ ). Worth noting is that

298 dogs from the outdoor setting with lower loadings exclusively were about to train 
agility, while the other main outdoor site with higher loadings consisted of different

300 kinds of obedience classes. Hence, the dogs on the two sites were about to perform

301 two quite different activities. No differences were found when comparing results from 302 the two different indoor environments.

304 Dividing the dogs depending on whether it was the first course day $(\mathrm{N}=39)$ or not $305(\mathrm{~N}=39)$ revealed dogs on the first course day to have higher PC scores for component 3061 (Social; fig. 3E; one-way ANOVA; $F(1,76)=20.3 ; p>0.001)$ suggesting that the 307 familiarity of the situation/environment also affects the behaviour of the dog.

\section{Comparing the two PCAs}

310 Comparing the two PCAs $(\mathrm{N}=78)$ showed that scores on component 1 (Social) from

311 both test parts strongly correlated with each other (fig. 4A; Pearson's correlation;

$312 \mathrm{r}=0.48 ; p<0.001)$. Furthermore, scores on component 1 from part one (Social)

313 correlated with component 3 of part two (Curious and Contact; fig. 4B; Pearson's

314 correlation; $\mathrm{r}=0.31 ; p<0.01$ ) and component 3 of both PCAs (both named Curious; fig.

315 4C) correlated with each other (Pearson's correlation; $\mathrm{r}=0.23 ; p<0.05$ ). In addition,

316 scores on component 4 from part one (Contact) correlated negatively to component 1

317 from part two (Social; fig. 4D; Pearson's correlation; $\mathrm{r}=-0.40 ; p<0.001$ )).

\section{Separate behaviour items}

320 Correlating the cooperative scores (as assessed by the owners in the questionnaire)

321 with the separate behaviour items from part one $(\mathrm{N}=82)$ we found a positive

322 correlation with the frequency of looking at the owner (Spearman's correlation;

$323 \mathrm{r}=0.36 ; p<0.01)$ and negative correlation with frequency of pulling the leash 
324 (Spearman's correlation; $\mathrm{r}=-0.32 ; p<0.01$ ). The cooperative score also correlated 325 positively to the PC 4 from part one (Contact; Spearman's correlation; $\mathrm{r}=0.27$; $p<$

326 0.05) and negatively to the PC 1 and PC 2 for part two (Social and Explorative;

327 Spearman's correlation; $-0.23 ; p<0.5$ and $\mathrm{r}=-0.30 ; p<0.01$ respectively). No

328 significant age or sex differences were found for the behaviour looking at owner

329 (Mann Whitney $\mathrm{U} ; \mathrm{U}=848.5$ and $\mathrm{U}=620.0$ respectively; $p=0.91$ and $p=0.10$

330 respectively), but young dogs ( $\leq 2$ years) pulled the leash more often than adults $(>2$

331 years; Mann Whitney $\mathrm{U} ; \mathrm{U}=550.5 ; p<0.01$ ). No correlation was found between

332 looking at owner and looking at the stranger (Spearman's correlation; $r=0.18$;

$333 p=0.10)$. None of the other seven owner scores were significantly correlated to any

334 behaviour results (see supplementary table 2 for mean values).

335

336 We found differences in both part one and part two between dogs on their first course

337 day and dogs attending their second day or later during the course. Dogs tested later

338 during the course ( $\geq 2$ course day) looked more often at their owner than dogs on

339 course day one (Table 4). The opposite was found for looking, pulling and jumping

340 towards other dogs (Table 4).

341

342 Interestingly, examining sex differences from part one, we found that females $(\mathrm{N}=31)$

343 jumped significantly more on their owners than males $(\mathrm{N}=51$; Mann Whitney $\mathrm{U}$;

$344 \mathrm{U}=603.5 ; p<0.05)$. Male dogs instead pulled the leash significantly more than

345 females (Mann Whitney $\mathrm{U} ; \mathrm{U}=1032.0 ; p<0.05$ ) if pulling towards other dogs was

346 excluded. There was no significant difference between female and male dogs in

347 course experience (Mann Whitney $\mathrm{U} ; \mathrm{U}=825.5 ; p=0.69$ ), experience of the owner 
348 (Mann Whitney $\mathrm{U} ; \mathrm{U}=922.0 ; p=0.53$ ), or in age distribution of the dogs (Mann

349 Whitney $\mathrm{U} ; \mathrm{U}=847.5 ; p=0.90)$.

\section{Discussion}

353 The aim of this study was to develop and test a simple way of obtaining a detailed

354 behaviour assessment of dogs in a situation which would reflect as much as possible

355 of their everyday situation, while still being performed in a standardised and

356 controlled manner, using quantitative ethological methods. We found that it is quite

357 feasible to quantify behavioural variation among dogs, including central aspects of

358 human- and dog-directed social behaviour, based on a very short period of

359 observations in a standardised, low-fearful situation for the dog. The test we applied

360 resembles everyday experiences of many companion dogs in western countries; it

361 does not expose the dogs to any obvious or intentional frightening stimuli, and allows

362 an assessment of the unaffected behaviour towards owners, a stranger and other dogs.

363 High correlations between the PCA scores in the first and second parts of the test

364 indicate consistent behaviour profiles. However, PC 2 from both PCAs (both labelled

365 Explorative) did not significantly correlate with each other. The most probable

366 explanation for this is that the PCA from part two are lacking behaviour items such as

367 move, stand and sit (since the dogs are walking during part two), which all have large

368 influence on PC 2 (Explorative) in part one.

370 Furthermore, the fact that the behaviour scores were highly consistent with the

371 subjective cooperative score in the owner assessments of the dogs indicates that the

372 test captured important elements of the normal behaviour. In addition, besides 
373 behavioural differences due to sex and age our results reveal that both home and test

374 environment influenced the behaviour of the dog, e.g. number of dogs living together,

375 whether the dog had access to a garden, whether the test was performed indoors or

376 outdoors, and also the familiarity of the situation/environment.

378 There are few studies on companion dog behaviour in their normal environment.

379 Udell [21] showed that dogs were better in a following pointing gestures test when

380 tested at home than if tested in an outdoor area suggesting that familiarity of the

381 environment affects their behaviour. Similarly, a recent study video-recorded dogs

382 and their owners on walks both in the city centre and in green areas to evaluate the

383 dog-owner contact [22]. Interestingly, when comparing the eye contact behaviour in

384 their study with results from standardised tests in laboratory environment, the dogs

385 paid much more attention towards their owner in laboratory environment than under

386 natural conditions [22,23]. Besides the fact that the dog performed different tasks, the

387 difference could also be caused by the new situations being perceived as stressful,

388 indicating that the commonly used behaviour tests may not always reflect the normal

389 dog behaviour. Further supporting this, hormonal analysis of dogs in dog parks show

390 that cortisol correlated negatively with the frequency of visiting the park [24] and

391 repeated DMAs found that fearful and aggressive behaviours decreased and

392 exploratory behaviour increased from first to second test [6]. Consistent with those

393 results, we found differences in behaviour depending on whether it was the first

394 course day for the dog or not. Even though our test did not include any stimuli that

395 were obviously fearful, some dogs might have perceived some parts of the test as

396 stressful or even fearful. The differences in frequency of looking at the owner (i.e.

397 probably seeking eye contact with owner) and also looking, pulling and jumping 
towards other dog between dogs on their $1^{\text {st }}$ course day and dogs attending their $2^{\text {nd }}$ day or later during the course could possibly be related to the familiarity of the environment and their advancement in training. This could imply that the dog

401 becomes progressively more attentive towards their owner and less concerned with

402 the surroundings. Hence, the familiarity of the environment and also the dog's

403 possible progress in training could matter for the dog's behaviour.

405 Our results indicate that not only the test environment but also the home environment 406 influences the behaviour of the dog in the present test. Those being the only dog in the 407 household showed more explorative and restless behaviour than those with dog 408 companions and dogs living in apartments were more explorative than those living 409 with access to a garden. However, in behavioural studies on pointing comprehension $410[25,26]$ neither the housing condition, nor the location of the testing affected the 411 performance of the dog. The latter is in contrast with Udell's study, where dogs in 412 their home environment showed better performance [21]. Worth noting when 413 comparing our results to these studies is that we neither trained nor tested the dogs but 414 only observed their behaviour when the dogs were affected only by stimuli of a low415 stressful and everyday character.

417 Young dogs have been suggested to be bolder than older dogs [18]. In studies on 418 beagles [27] young dogs were more explorative and interacted more with novel toys, 419 humans, and a model dog than old dogs. This corresponds well with our results where 420 young dogs scored high for the components Social and Explorative. These results at 421 least to some extent validate our method used in this study. 
423 With respect to sex differences, females jumped more on their owners, hence sought

424 more physical contact, than male dogs. Similar sex differences were found in a recent

425 behavioural test of approximately 500 laboratory beagles [28]. However, none of the

426 studies observed any sex differences in contact behaviours other than physical

427 contact, i.e. there was no sex differences in looking up at owner or stranger, which is

428 similar to results from pointing comprehension studies [26].

430 One drawback with studying several dogs simultaneously is the possibility for dogs to

431 influence each other in an uncontrolled way, and this could have an effect on the

432 behaviour of some individuals. However, our aim was to develop a simple test to

433 study dogs' behaviour in the presence of other dogs since we believe this to be an

434 important part of the normal life of a dog and something that is often missed out on in

435 common test batteries. For future studies, we suggest that important test development

436 could include testing the dogs repeatedly on different occasions. If a stable assessment

437 of a single dog's behaviour is required, it could be argued that they should always be

438 tested on for example both first and fifth class to evaluate whether the behaviour is

439 stable over time.

441 Together with a validated questionnaire (e.g. Canine Behavioral Assessment and

442 Research Questionnaire) this behavioural assessment could be a more complete

443 description of a dog's behaviour, also including social behaviours towards other dogs.

444 Hopefully, in future application it will be possible to focus on the frequency of certain

445 key behaviours and this could be a promising start to finding candidate genes for

446 social behaviour. 
The present method offers a simple and rapid way of collecting quantitative behaviour data with a controlled and standardised procedure. However, due to our differences in results from different test environments we would suggest to perform future tests in

451 only one type of setting, e.g. only outdoors in an open field. Also, if visiting dog

452 classes it could be wise to consider that dogs attending an active training class such as

453 agility or tracking might differ in behaviour and excitement from dogs in various

454 obedience classes because of differences in situational expectations.

Unlike most available, commonly used behavioural test batteries, the present method

457 utilises a situation where dog owners voluntarily take their companion dogs to

458 training classes, and where we do not deliberately expose dogs to the plethora of

459 frightening and stressful situations commonly associated with different sorts of

460 mentality assessment tests. We suggest that the present test has the potential of

461 providing a more precise and unbiased assessment of variation in everyday behaviour

462 in the companion dog population. The demands for such assessment is growing as

463 dogs are more frequently used in behaviour genetics, which requires behavioural

464 assessment of a large number of dogs, and in studies focusing on welfare problems

465 among companion dogs [4,29].

\section{Conclusion}

468 We developed a simple method for assessing dog behaviour in a social and everyday

469 setting. The validity of the method was demonstrated by consistency in behavioural

470 ratings between different test parts, agreement with some questions in the owner

471 assessments and by the fact that many of the effects observed were consistent with

472 earlier published experiments. Our results show that the dog's age and the 
473

474

475

476

477

environment, both at home and during the test, influence the dog's social and explorative behaviour. Dogs perceived as cooperative by their owner look more often up at their owner and also pull the leash less than other dogs. In addition we found some sex differences, e.g. females jumped more than male dogs on their owner. With this simple and fast method, we have shown that it is possible to evaluate dog behaviour from only a couple of minutes of detailed behaviour recordings in a standardised everyday context.

\section{Acknowledgements}

We are grateful to all dog owners that volunteered for this experiment and also to the dog instructors who allowed us to steal some minutes from their courses. We thank AS Sundman and M Persson for discussions on methods and statistics and help with a few video-recordings and we also thank the reviewer for valuable comments on the manuscript. The project was performed within the framework of the Swedish Center of Excellence in Animal Welfare Science, financed by Formas. The project was funded by the European Research Council (ERC) within the advanced grant “GENEWELL" (322206).

\section{Ethical considerations}

No special permission for use of privately owned dogs in non-invasive observational studies is required in Sweden, Still, all experiments in this paper were conducted in line with ethical approval from the regional ethical committee for animal experiments in Linköping, Sweden (Permit number: 51-13). 


\section{Conflict of interest statement}

The authors declare no conflict of interest.

\section{Authorship statement}

The idea for the paper and the design of the experiment was conceived by both LSV

504 Roth and P Jensen. Experiments and data analyses were performed by LSV Roth while both authors were involved in the interpretation of the results and the development of the manuscript. Both authors have approved the final article.

\section{References}

509
1. Clutton-Brock J (1981) Domesticated animals from early times. London:
Heinemann and British Museum (Natural History).

2. Vilà C, Savolainen P, Maldonado JE, Amorim, IR, Rice JE. et al. (1997) Multiple and ancient origins of the domestic dog. Science 276: 16871689.

3. Udell MAR, Wynne CDL (2008) A review of domestic dogs' (Canis familiaris) human-like behaviors: or why behavior analysts should stop worrying and love their dogs. J Exp Anal Behav 89: 247-261.

4. Yokoyama JS, Hamilton SP (2012) Genetics of Canine Behavioural Disorders. In: Ostrander EA, Ruvinsky A, editors. The Genetics of the Dog, 2nd Edition. Cambridge: CABI. pp.275-294.

5. Jones AC, Gosling SD (2005) Temperament and personality in dogs (Canis familiaris): A review and evaluation of past research. Appl Anim Behav Sci 95: 1-53.

6. Svartberg K, Tapper I, Temrin H, Radesäter T (2005) Consistency of personality traits in dogs. Anim Behav 69: 283-291.

7. Murphy JA (1998) Describing categories of temperament in potential guide dogs for the blind. Appl Anim Behav Sci 58: 3-178. 
8. $\quad$ Foyer P, Bjällerhag N, Wilsson E, Jensen P (2014) Behaviour and experiences of dogs during the first year of life predict the outcome in a later temperament test. Appl Anim Behav Sci 155: 93-100.

9. $\quad$ Arvelius P, Strandberg E, Fikse WF (2014) The Swedish Armed Forces temperament test gives information on genetic differences between dogs. J Vet Behav: 1-35.

10. Wilsson E, Sundgren PE (1997) The use of a behaviour test for selection of dogs for service and breeding. II. Heritability for tested parameters and effect of selection based on servicedog characteristics. Appl Anim Behav Sci 54: 235-241.

11. Svartberg K (2005) A comparison of behaviour in test and in everyday life: evidence of three consistent boldness-related personality traits in dogs. Appl Anim Behav Sci 91: 103-128.

12. Svartberg K, Forkman B (2002) Personality traits in the domestic dog (Canis familiaris). Appl Anim Behav Sci 79: 133-155.

13. Svartberg K (2006) Breed-typical behaviour in dogs - Historical remnants or recent constructs? Appl Anim Behav Sci 96: 293-313.

14. Lund JD, Agger JF, Vestergaard KS (2004) Reported behaviour problems in pet dogs in Denmark: age distribution and influence of breed and gender. Prev Vet Med 28: 33-48.

15. Fatjó J, Ruiz-de-la-Torre JL, Manteca X (2006) The epidemiology of behavioural problems in dogs and cats: a survey of veterinary practitioners. Anim Welfare 15: 179185.

16. Mongillo P, Pitteri E, Carnier P, Gabai G, Adamelli S, Marinelli L. (2013) Does the attachment system towards owners change in aged dogs? Physiol Behav 120: 64-69.

17. Serpell JA, Hsu Y (2005) Effects of breed, sex, and neuter status on trainability in dogs. Anthrozoos 18: 196-207.

18. Starling MJ, Branson N, Thomson PC, McGreevy PD (2013) Age, sex and reproductive status affect boldness in dogs. Vet J 197: 868-872.

19. Mirkó E, Dóka A, Miklósi Á (2013) Association between subjective rating and behaviour coding and the role of experience in making video assessments on the personality of the domestic dog (Canis familiaris). Appl Anim Behav Sci 149: 45-54.

20. Meyer I, Forkman B (2014) Dog and owner characteristics affecting the dog-owner relationship. J Vet Behav 9: 143-150.

21. Udell M, Dorey NR, Wynne CDL (2008) Wolves outperform dogs in following human social cues. Anim Behav 76: 1767-1773. 
22. Mongillo P, Adamelli S, Pitteri E, Marinelli L (2014) Reciprocal attention of dogs and owners in urban contexts. J Vet Behav 9:158-163.

23. Horn L, Range F, Huber L (2012) Dogs' attention towards humans depends on their relationship, not only on social familiarity. Anim Cogn 16: 435-443.

24. Ottenheimer-Carrier L, Cyr A, Anderson RE, Walsh CJ (2013) Exploring

25. Pongrácz P, Gácsi M, Hegedüs D, Péter A, Miklósi Á (2013) Test the dog park: Relationships between social behaviours, personality and sensitivity is important for detecting variability in pointing comprehension in canines. Anim Cogn 16: 721-735.

28. Persson M, Roth LSV, Johnson M, Wright, D, Jensen P (in press)

Gácsi M, Kara E, Belényi B, Topál J, Miklósi Á (2009) The effect of development and individual differences in pointing comprehension of dogs. Anim Cogn 12: 471-479.

Siwak CT (2001) Effect of age and level of cognitive function on spontaneous and exploratory behaviors in the beagle dog. Learn Mem 8: 317-325. Human-directed social behaviour in dogs shows significant heritability. Genes, Brain and Behavior. 


\section{$593 \quad$ Figure legends}

594

595

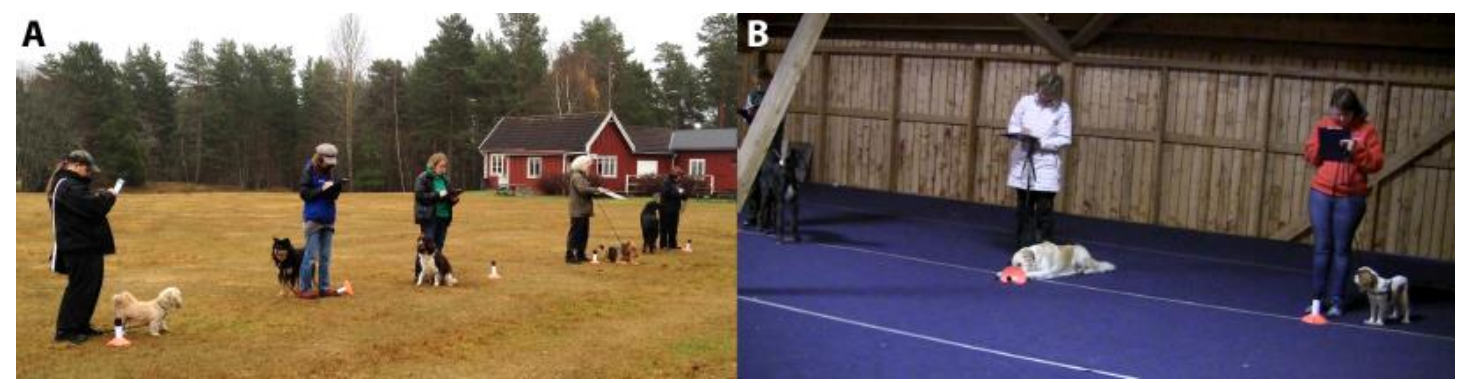

596 Figure 1. Pictures of representative outdoor (A) and indoor (B) test environments. 597 During the first part of the test, owners were asked to stand with their dogs behind an 598 orange cone, and during the second part to walk their dogs in a circle around all the 599 cones.

600 

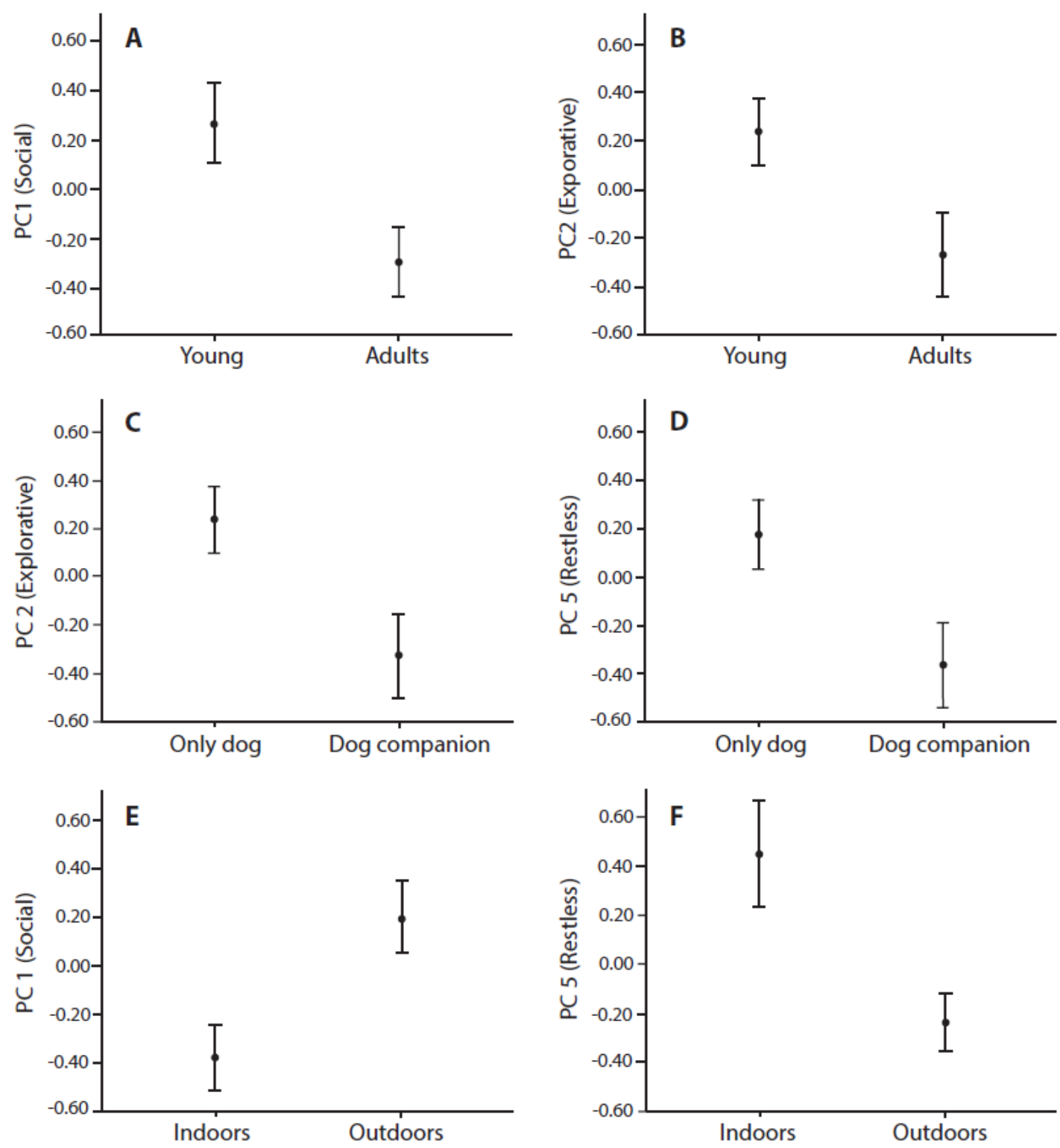

603 Figure 2. Scores ( \pm 1 SEM) from the Principal Component analysis of part one of the test ( $3 \mathrm{~min}$ by the cone). The panels show the significant effects of items from the questionnaires on the component scores. A: Young vs adult dogs, scores on PC 1 (Social). B: Young vs adult dogs, scores on PC 2 (Explorative). C: Only dog in household vs dogs with other companion dogs, scores on PC 2 (Explorative). D: Only dog in household vs dogs with other companion dogs, scores on PC 5 (Restless). E: Test conducted during an indoor vs outdoor course, scores on PC 1 (Social). F: Test conducted during an indoor vs outdoor course, scores on PC 5 (Restless). G: Dog tested on its first day attending the course vs later during the course, scores on PC 4 (Contact). 

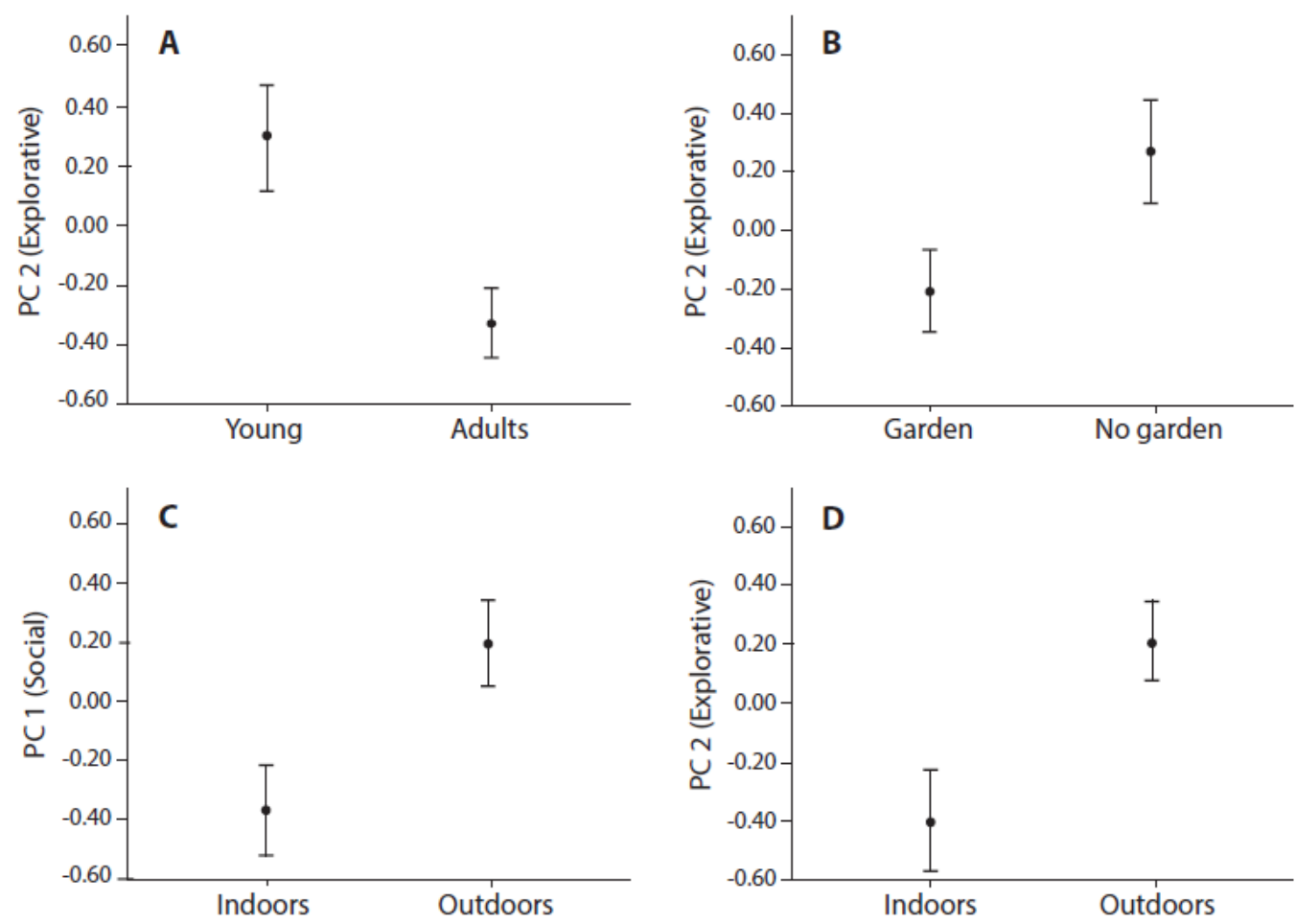

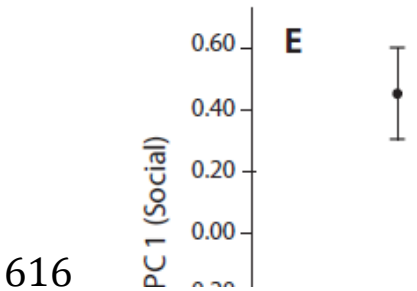

617 Figure 3. Scores ( \pm 1 SEM) from the Principal Component analysis of part two of the test (30 s of walking). The panels show the significant effects of items from the questionnaires on the component scores. A: Young vs adult dogs, scores on PC 2 (Explorative). B: Dogs with access to garden vs no such access, scores on PC 2 (Explorative). C: Test conducted during an indoor vs outdoor course, scores on PC 1 (Social). D: Test conducted during an indoor vs outdoor course, scores on PC 2 (Explorative). E: Dog tested on its first day attending the course vs later during the course, scores on PC 1 (Social). 

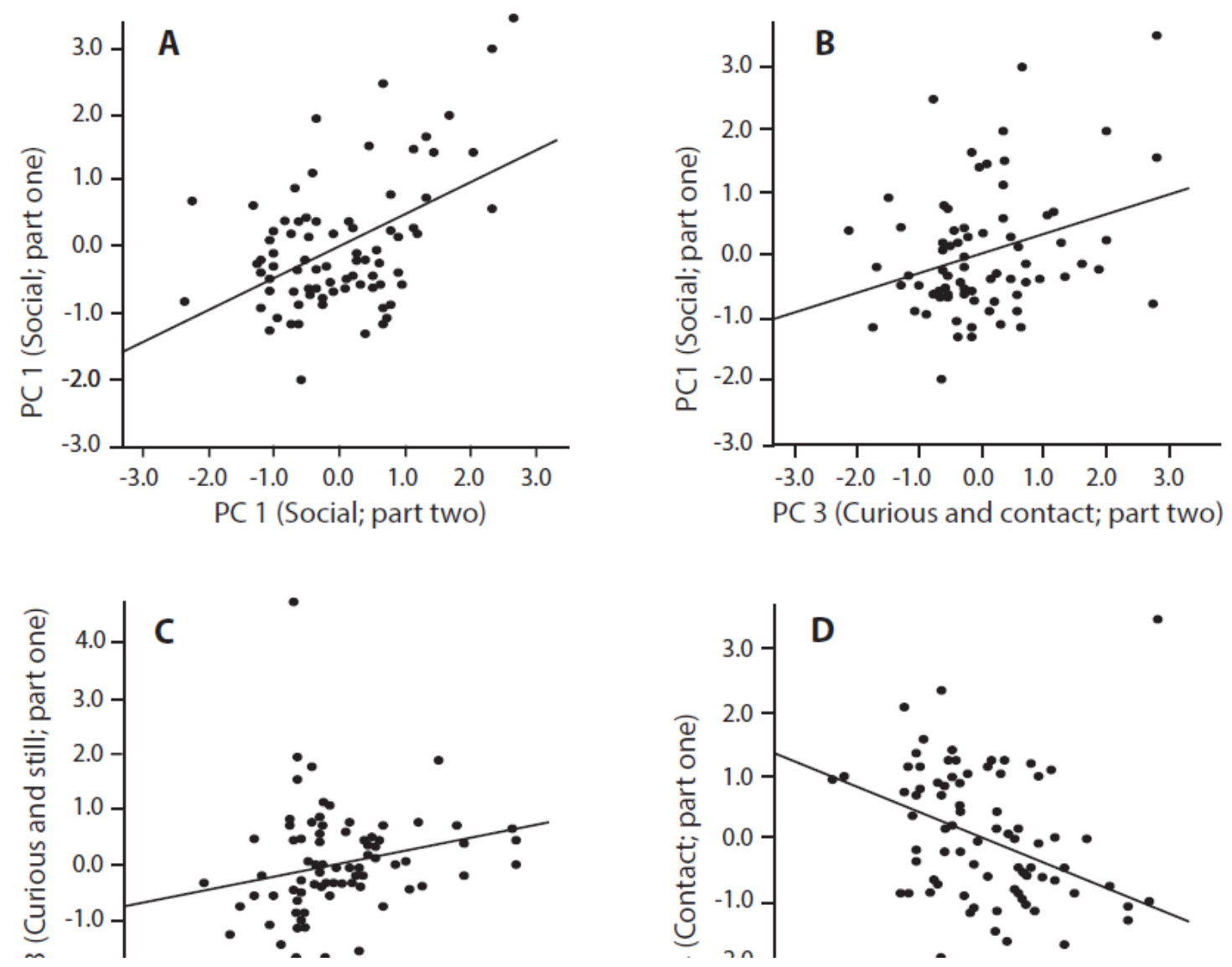

630 Figure 4. Plots of individual component scores from the two different test parts. The panels show those cases where a significant correlation between the scores was found, together with the trend lines. A: PC 1 (Social) from part one vs PC 1 (Social) from part two. B: PC 1 (Social) from part one vs PC 3 (Curious and contact) from part two. C: PC 3 (Curious and still) from part one vs PC 3 (Curious and contact) from part two. D: PC 4 (Contact) from part one vs PC 1 (Social) from part two. 
1 Table 1. Ethogram of the behaviours of the dog used in the analyses.

Behaviour Definition

\section{Novel Object}

Looks at

Sniffs

Physical

\section{Owner}

Looks at

Jumps on

\section{Other dogs}

Looks at

Pulls towards

Jumps towards

\section{Stranger}

Looks at stranger

Moves towards

Sniffs

Jumps on

Looks at owner

\section{Other}

Stands

Sits

Lies down

Moves

Pulls

Sniffs the ground

Yawns

Shakes

Vocalisation
Head directed towards the novel object

Stretches the neck and head towards the novel object

Physical contact with the novel object

Head directed towards the owners face

$\leq 2$ paws on the ground, makes physical contact with the owner

Head towards another dog

Pulls the leash towards another dog

$\leq 2$ paws in contact with ground, head directed towards another dog

Head directed towards the stranger

Moves towards the stranger

Stretches his/her neck and head towards the stranger

$\leq 2$ paws on the ground, makes physical contact with the stranger

Head directed towards the owner within $5 \mathrm{sec}$ before or after stranger interaction

Stands up with all four legs and do not move

The behind is in contact with ground, forelegs are standing

Belly in contact with the ground

Moves at least one paw to new location

Stretches the leash towards other things than other dogs

Stretches his/her neck with the nose close to the ground

Widely opens his/her mouth

Repeatedly and rapidly moves the body left-right

Generates whining or barking noise 
Table 2. Principal component analysis, showing component loadings of the behavioural variables from part one of the test $(3 \mathrm{~min}$ by the novel object), where bold values have largest impact on the component.

\begin{tabular}{lrrrrr}
\hline Principle component & Social & Explorative & $\begin{array}{c}\text { Curious/ } \\
\text { Still }\end{array}$ & Contact & Restless \\
\hline Pulls toward dog & $\mathbf{0 . 8 4}$ & 0.05 & -0.05 & -0.29 & -0.15 \\
Jumps toward dog & $\mathbf{0 . 7 7}$ & -0.01 & 0.04 & -0.31 & -0.13 \\
Moves towards stranger & $\mathbf{0 . 7 7}$ & 0.04 & 0.16 & 0.26 & 0.3 \\
Jumps towards stranger & $\mathbf{0 . 7 4}$ & 0.05 & 0.21 & -0.19 & 0.21 \\
Sniffs stranger & $\mathbf{0 . 7}$ & 0.09 & 0.27 & 0.25 & 0.25 \\
Jumps on owner & $\mathbf{0 . 5}$ & 0.15 & 0.27 & 0.07 & -0.09 \\
Barks & $\mathbf{0 . 4 5}$ & -0.12 & 0.06 & 0.05 & -0.24 \\
Lies down & $\mathbf{- 0 . 3 6}$ & -0.09 & $\mathbf{0 . 3 6}$ & $\mathbf{- 0 . 3 5}$ & 0.08 \\
Moves & $\mathbf{0 . 5}$ & $\mathbf{0 . 6 3}$ & $\mathbf{- 0 . 4 1}$ & 0.11 & 0.1 \\
Stands & $\mathbf{0 . 3 8}$ & $\mathbf{0 . 6 4}$ & $\mathbf{- 0 . 5 1}$ & 0.23 & -0.12 \\
Looks at dog & $\mathbf{0 . 5 3}$ & $\mathbf{- 0 . 4 8}$ & -0.01 & -0.33 & -0.13 \\
Sniffs the ground & $\mathbf{- 0 . 3 6}$ & $\mathbf{0 . 4 5}$ & $\mathbf{- 0 . 6}$ & 0.19 & 0.15 \\
Looks at stranger & $\mathbf{0 . 3 5}$ & $\mathbf{- 0 . 3 6}$ & 0.31 & $\mathbf{0 . 3 6}$ & -0.02 \\
Sits & -0.16 & $\mathbf{- 0 . 6 7}$ & 0.31 & -0.03 & 0.17 \\
Looks at novel object & -0.2 & $\mathbf{0 . 7}$ & $\mathbf{0 . 6 1}$ & -0.14 & 0.1 \\
Sniffs at novel object & -0.18 & $\mathbf{0 . 6 8}$ & $\mathbf{0 . 6 4}$ & -0.15 & 0.03 \\
Physical with novel object & -0.12 & $\mathbf{0 . 6 1}$ & $\mathbf{0 . 7 1}$ & -0.19 & -0.07 \\
Pulls (not towards dogs) & -0.1 & $\mathbf{0 . 3 7}$ & -0.27 & -0.15 & 0.11 \\
Looks at owner & -0.09 & -0.06 & $\mathbf{0 . 4 4}$ & $\mathbf{0 . 6 7}$ & -0.04 \\
Looks at owner (stranger) & -0.04 & -0.03 & 0.31 & $\mathbf{0 . 7 2}$ & $\mathbf{- 0 . 3 7}$ \\
Yawns & -0.07 & -0.26 & 0.1 & -0.04 & $\mathbf{0 . 7 1}$ \\
Shakes & 0.11 & 0.06 & -0.13 & 0.32 & $\mathbf{0 . 5 3}$ \\
\hline Explained variation $(\%)$ & 21 & 16 & 14 & 9 & 6 \\
\hline & & & & &
\end{tabular}


Table 3. Principal component analysis, showing component loadings of the behavioural variables from the second part of the test (30 sec of walking), where bold values have largest impact on the component.

\begin{tabular}{lrcrc}
\hline Principle component & Social & Explorative & $\begin{array}{r}\text { Curious/ } \\
\text { Contact }\end{array}$ & Restless \\
\hline Looks at dog & $\mathbf{0 . 7 4}$ & -0.11 & -0.01 & 0.02 \\
Jumps towards dog & $\mathbf{0 . 7 3}$ & 0.15 & $\mathbf{0 . 3 3}$ & 0.09 \\
Barks & $\mathbf{0 . 3 5}$ & -0.23 & $\mathbf{0 . 4 4}$ & 0.22 \\
Looks at novel object & $\mathbf{- 0 . 3 4}$ & $\mathbf{0 . 7 1}$ & $\mathbf{0 . 3 9}$ & -0.2 \\
Sniffs at novel object & $\mathbf{- 0 . 3 6}$ & $\mathbf{0 . 6}$ & $\mathbf{0 . 4 7}$ & -0.05 \\
Looks at owner & $\mathbf{- 0 . 5 2}$ & $\mathbf{- 0 . 5 9}$ & $\mathbf{0 . 4}$ & -0.08 \\
Pulls towards dog & $\mathbf{0 . 8 2}$ & $\mathbf{0 . 3 6}$ & 0.08 & 0.1 \\
Sniffs the ground & $\mathbf{- 0 . 3 7}$ & $\mathbf{0 . 3 4}$ & $\mathbf{- 0 . 4 5}$ & 0.1 \\
Physical with novel object & -0.24 & $\mathbf{0 . 6}$ & 0.3 & 0.33 \\
Jumps at owner & -0.16 & $\mathbf{- 0 . 4 1}$ & $\mathbf{0 . 5 2}$ & $\mathbf{0 . 3 6}$ \\
Pulls (not towards dogs) & 0.23 & $\mathbf{0 . 6 8}$ & -0.08 & -0.12 \\
Shakes & -0.2 & 0.17 & -0.31 & $\mathbf{0 . 8 1}$ \\
\hline Explained variation $(\%)$ & 23 & 21 & 13 & 9 \\
\hline
\end{tabular}


Table 4: Average minimum frequencies (due to 1/0 sampling method) of separate behaviour items in both part one and part two of the test depending on course day that the test was conducted. P-values were calculated with Mann Whitney U Test.

\begin{tabular}{|c|c|c|c|c|c|c|}
\hline \multirow[b]{2}{*}{ Part one } & \multirow{2}{*}{$\begin{array}{l}\text { Behaviour } \\
\text { Look at owner }\end{array}$} & \multicolumn{2}{|c|}{$\begin{array}{c}\text { Mean } \\
\pm \text { SEM during } \\
1^{\text {st }} \text { course day }\end{array}$} & \multicolumn{2}{|c|}{$\begin{array}{c}\text { Mean } \\
\pm \text { SEM during } \\
\geq 2^{\text {nd }} \text { course day }\end{array}$} & \multirow{2}{*}{$\begin{array}{c}\mathbf{P} \\
0.001\end{array}$} \\
\hline & & $7.0 \pm 0.9$ & $(\mathrm{~N}=39)$ & $10.9 \pm 0.8$ & $(\mathrm{~N}=43)$ & \\
\hline & Look at dog & $24.3 \pm 1.5$ & $(\mathrm{~N}=40)$ & $18.0 \pm 1.2$ & $(\mathrm{~N}=43)$ & 0.002 \\
\hline & Pull towards dog & $5.7 \pm 1.2$ & $(\mathrm{~N}=40)$ & $2.3 \pm 0.5$ & $(\mathrm{~N}=43)$ & 0.030 \\
\hline & $\begin{array}{l}\text { Jump towards } \\
\text { dog }\end{array}$ & $2.3 \pm 0.7$ & $(\mathrm{~N}=40)$ & $0.4 \pm 0.2$ & $(\mathrm{~N}=43)$ & 0.010 \\
\hline \multirow[t]{4}{*}{ Part two } & Look at owner & $1.7 \pm 0.3$ & $(\mathrm{~N}=39)$ & $3.1 \pm 0.3$ & $(\mathrm{~N}=43)$ & 0.003 \\
\hline & Look at dog & $5.0 \pm 0.2$ & $(\mathrm{~N}=39)$ & $3.8 \pm 0.3$ & $(\mathrm{~N}=43)$ & 0.003 \\
\hline & Pull towards dog & $2.9 \pm 0.3$ & $(\mathrm{~N}=39)$ & $1.1 \pm 0.2$ & $(\mathrm{~N}=43)$ & 0.000 \\
\hline & $\begin{array}{l}\text { Jump towards } \\
\text { dogs }\end{array}$ & $0.8 \pm 0.2$ & $(\mathrm{~N}=39)$ & $0.2 \pm 0.1$ & $(\mathrm{~N}=43)$ & 0.011 \\
\hline
\end{tabular}




\begin{tabular}{|c|c|c|c|c|c|c|c|c|c|c|c|}
\hline & Course & In/Out & $\begin{array}{r}\text { Owner } \\
\text { age }\end{array}$ & Breed & $\begin{array}{r}\text { Dog age } \\
\text { (months) }\end{array}$ & $\begin{array}{r}\text { Age } \\
\text { category }\end{array}$ & Female/Male & Garden/Apartment & $\begin{array}{r}1 \text { or } \geq 2 \text { dogs } \\
\text { at home }\end{array}$ & $\begin{array}{l}\text { Dog been on } \\
\text { course before }\end{array}$ & $\begin{array}{c}\text { Owner } \\
\text { experience (1-3) }\end{array}$ \\
\hline 1 & puppy & 01 & 14 & Border collie & 5 & 1 & $\mathrm{~F}$ & garden & 1 & $\mathrm{~N}$ & 1 \\
\hline 2 & puppy & 01 & 24 & Poodle & 6 & 1 & M & app & 2 & $\mathrm{~N}$ & 1 \\
\hline 3 & puppy & 01 & 64 & Poodle & 5 & 1 & M & app & 1 & $\mathrm{~N}$ & 1 \\
\hline 4 & puppy & 01 & 25 & Poodle & 60 & 2 & M & app & 2 & $\mathrm{~N}$ & 1 \\
\hline 5 & puppy & 01 & 39 & Poodle/Golden & 6 & 1 & M & garden & 1 & $\mathrm{~N}$ & 1 \\
\hline 6 & obedience & 01 & 28 & Labrador/Drever & 22 & 1 & $\mathrm{~F}$ & app & 1 & $\mathrm{Y}$ & 2 \\
\hline 7 & obedience & 01 & 47 & Ridgeback & 36 & 2 & M & garden & 1 & $\mathrm{Y}$ & 2 \\
\hline 8 & obedience & 01 & 21 & Chihuahua/pincher & 22 & 1 & M & app & 1 & $\mathrm{Y}$ & 2 \\
\hline 9 & obedience & 01 & 34 & Schnauzer & 24 & 1 & $\mathrm{~F}$ & garden & 1 & $\mathrm{Y}$ & 2 \\
\hline 10 & obedience & I1 & 50 & Lagotto & 24 & 1 & $\mathrm{~F}$ & garden & 1 & $\mathrm{Y}$ & 2 \\
\hline 11 & obedience & 11 & 49 & Jack russell terrier & 36 & 2 & $\mathrm{~F}$ & garden & 1 & $\mathrm{Y}$ & 2 \\
\hline 12 & obedience & 11 & 12 & Welsh springer spaniel & 20 & 1 & $\mathrm{~F}$ & garden & 2 & $\mathrm{Y}$ & 2 \\
\hline 13 & obedience & 11 & 26 & Golden retriever & 36 & 2 & $\mathrm{~F}$ & garden & 1 & $\mathrm{Y}$ & 1 \\
\hline 14 & obedience & 11 & 38 & Labrador & 8 & 1 & M & garden & 1 & $\mathrm{~N}$ & 1 \\
\hline 15 & obedience & 11 & 22 & Scottish deerhound & 5 & 1 & M & app & 2 & $\mathrm{~N}$ & 3 \\
\hline 16 & obedience & 11 & 46 & Border collie / Golden & 20 & 1 & M & garden & 1 & $\mathrm{Y}$ & 2 \\
\hline 17 & obedience & 11 & 20 & Cavalier king charles spaniel & 9 & 1 & M & app & 1 & $\mathrm{~N}$ & 1 \\
\hline 18 & puppy & 01 & 48 & French bulldog & 4 & 1 & M & app & 1 & $\mathrm{~N}$ & 1 \\
\hline 19 & puppy & 01 & 22 & Siberian Alaskan malamute & 5 & 1 & M & app & 1 & $\mathrm{~N}$ & 1 \\
\hline 20 & puppy & 01 & 28 & Lancashire heeler & 6 & 1 & M & garden & 1 & $\mathrm{~N}$ & 1 \\
\hline 21 & puppy & 01 & 65 & Lagotto & 5 & 1 & $\mathrm{~F}$ & garden & 1 & $\mathrm{~N}$ & 1 \\
\hline 22 & puppy & 01 & 23 & Swedish lapphund & 3 & 1 & M & app & 1 & $\mathrm{~N}$ & 1 \\
\hline 23 & puppy & 01 & 45 & Chihuahua/Papillon & 5 & 1 & $\mathrm{~F}$ & garden & 1 & $\mathrm{~N}$ & 1 \\
\hline 24 & puppy & 01 & 66 & Dachshund & 6 & 1 & M & app & 1 & $\mathrm{~N}$ & 1 \\
\hline 25 & puppy & 01 & 66 & Lagotto & 5 & 1 & $\mathrm{~F}$ & garden & 1 & $\mathrm{~N}$ & 1 \\
\hline 26 & obedience & 01 & & Mixed breed & 9 & 1 & $\mathrm{~F}$ & app & 1 & $\mathrm{~N}$ & 2 \\
\hline 27 & obedience & 01 & 28 & French bulldog & 18 & 1 & M & app & 1 & $\mathrm{Y}$ & 2 \\
\hline 28 & obedience & 01 & 48 & Spanish waterdog & 15 & 1 & M & app & 1 & $\mathrm{Y}$ & 2 \\
\hline 29 & Freestyle & I1 & 38 & Border collie & 30 & 2 & M & garden & 2 & $\mathrm{~N}$ & 3 \\
\hline 30 & Freestyle & 11 & 31 & Poodle & 18 & 1 & M & app & 1 & $\mathrm{Y}$ & 2 \\
\hline 31 & Freestyle & 11 & & Springer spaniel & 84 & 2 & M & app & 1 & $\mathrm{Y}$ & 2 \\
\hline 32 & Freestyle & 11 & & $\begin{array}{l}\text { schnauzer } \\
\text { Japanese spitz/Cavalier king }\end{array}$ & 42 & 2 & M & app & 1 & $\mathrm{Y}$ & 3 \\
\hline 33 & Freestyle & 11 & 17 & Charles Spaniel & 24 & 1 & M & garden & 1 & $\mathrm{Y}$ & 2 \\
\hline 34 & Freestyle & 11 & 51 & Shetland sheepdog & 36 & 2 & M & garden & 2 & $\mathrm{Y}$ & 3 \\
\hline 35 & Freestyle & 11 & 36 & Welsh springer spaniel & 60 & 2 & M & garden & 2 & $\mathrm{Y}$ & 3 \\
\hline 36 & Freestyle & I1 & 34 & Rottweiler & 66 & 2 & $\mathrm{~F}$ & garden & 1 & $\mathrm{Y}$ & 3 \\
\hline 37 & obedience & 01 & 27 & Flat coated retriever & 16 & 1 & M & garden & 1 & $\mathrm{Y}$ & 2 \\
\hline 38 & obedience & 01 & 23 & Staffordshire bull terrier & 18 & 1 & $\mathrm{~F}$ & app & 1 & $\mathrm{Y}$ & 2 \\
\hline 39 & obedience & 01 & 53 & Dachshund & 15 & 1 & M & app & 2 & $\mathrm{Y}$ & 2 \\
\hline 40 & obedience & 01 & 24 & Mixed breed & 9 & 1 & $\mathrm{~F}$ & garden & 1 & $Y$ & 2 \\
\hline 41 & obedience & 01 & 24 & Mongrel (Spain) & 20 & 1 & M & app & 1 & $\mathrm{Y}$ & 2 \\
\hline 42 & obedience & 12 & 43 & $\begin{array}{l}\text { Danish-Swedish farm dog } \\
\text { Cavalier king charles }\end{array}$ & 24 & 1 & M & app & 2 & $\mathrm{Y}$ & 3 \\
\hline 43 & obedience & 12 & 42 & Spaniel/Cocker spaniel & 22 & 1 & M & app & 1 & $\mathrm{Y}$ & 2 \\
\hline 44 & obedience & 12 & 63 & $\begin{array}{l}\text { Bedlington terrier } \\
\text { German shepherd dog/Siberian }\end{array}$ & 84 & 2 & M & app & 1 & $\mathrm{Y}$ & 2 \\
\hline 45 & obedience & 01 & 28 & husky & 48 & 2 & $\mathrm{~F}$ & app & 1 & $\mathrm{Y}$ & 2 \\
\hline 46 & obedience & 01 & 38 & English springer spaniel & 84 & 2 & M & app & 1 & $\mathrm{Y}$ & 2 \\
\hline 47 & obedience & 01 & 46 & Australian kelpie & 30 & 2 & M & app & 1 & $\mathrm{Y}$ & 2 \\
\hline
\end{tabular}




\begin{tabular}{|c|c|c|c|c|}
\hline 48 & obedience & 01 & 44 & Golden retriever \\
\hline 49 & obedience & 01 & 44 & Border collie \\
\hline 50 & obedience & 01 & 30 & $\begin{array}{l}\text { Am Staffordshire bullterrier } \\
\text { Nova Scotia duck tolling }\end{array}$ \\
\hline 51 & obedience & 12 & & retriever \\
\hline 52 & obedience & 12 & 53 & Dachshund \\
\hline 53 & obedience & 12 & 26 & Jack russell/German spitz \\
\hline 54 & obedience & 12 & 23 & $\begin{array}{l}\text { Mongrel } \\
\text { Mixed breed (Poodle-Coton de }\end{array}$ \\
\hline 55 & obedience & 12 & 47 & Tulean) \\
\hline 56 & obedience & 12 & 24 & Finish lapphund \\
\hline 57 & obedience & 12 & 35 & Mixed breed \\
\hline 58 & obedience & 12 & 51 & Swedish vallhund \\
\hline 59 & obedience & 12 & 46 & Flat-coated retriever \\
\hline 60 & tracking & $\mathrm{O} 4$ & 70 & Briard \\
\hline 61 & tracking & $\mathrm{O} 4$ & 36 & Boxer \\
\hline 62 & tracking & 04 & 26 & Shetland sheepdog \\
\hline 63 & tracking & $\mathrm{O} 4$ & 32 & Cirneco dell'etna \\
\hline 64 & tracking & 04 & 47 & Jack russell \\
\hline 65 & agility & 02 & 21 & Border collie \\
\hline 66 & agility & 02 & 48 & Border collie \\
\hline 67 & agility & 02 & 62 & Border collie \\
\hline 68 & agility & 02 & 48 & Border collie \\
\hline 69 & agility & $\mathrm{O} 2$ & 23 & Pumi \\
\hline 70 & agility & $\mathrm{O} 2$ & 44 & Danish-Swedish farm dog \\
\hline 71 & agility & $\mathrm{O} 2$ & 14 & Schapendoes \\
\hline 72 & agility & $\mathrm{O} 2$ & 55 & Pincher \\
\hline 73 & agility & $\mathrm{O} 2$ & 13 & Schnauzer \\
\hline 74 & agility & $\mathrm{O} 2$ & 34 & Rhodesian ridgeback \\
\hline 75 & agility & $\mathrm{O} 2$ & 51 & Briard \\
\hline 76 & agility & 02 & 56 & Chihuahua \\
\hline 77 & agility & 02 & 27 & Chihuahua \\
\hline 78 & agility & 02 & 50 & Pumi \\
\hline 79 & agility & $\mathrm{O} 2$ & 48 & Labrador \\
\hline 80 & agility & 02 & 24 & Lhasa apso \\
\hline 81 & agility & $\mathrm{O} 2$ & 18 & Finish lapphund \\
\hline 82 & agility & $\mathrm{O} 2$ & 49 & English springer spaniel \\
\hline 83 & agility & $\mathrm{O} 2$ & 54 & Airdale terrier \\
\hline 84 & agility & $\mathrm{O} 2$ & 54 & Hovawart \\
\hline 85 & obedience & 03 & 13 & Australian kelpie \\
\hline 86 & obedience & 03 & 32 & Golden retriever \\
\hline
\end{tabular}

$\begin{array}{rlll}48 & 2 & \mathrm{~F} & \text { app } \\ 6 & 1 & \mathrm{~F} & \text { garden } \\ 48 & 2 & \mathrm{~F} & \text { app } \\ & & \\ 18 & 1 & \mathrm{~F} & \text { garden } \\ 15 & 1 & \mathrm{M} & \text { app } \\ 6 & 1 & \mathrm{~F} & \text { app } \\ 36 & 2 & \mathrm{~F} & \text { app } \\ & & \\ 30 & 2 & \mathrm{M} & \text { garden } \\ 6 & 1 & \mathrm{M} & \text { app } \\ 30 & 2 & \mathrm{~F} & \text { app } \\ 16 & 1 & \mathrm{M} & \text { garden } \\ 42 & 2 & \mathrm{M} & \text { garden } \\ 30 & 2 & \mathrm{~F} & \text { garden } \\ 12 & 1 & \mathrm{~F} & \text { garden } \\ 18 & 1 & \mathrm{~F} & \text { garden } \\ 11 & 1 & \mathrm{M} & \text { app } \\ 10 & 1 & \mathrm{M} & \text { garden } \\ 72 & 2 & \mathrm{M} & \text { garden } \\ 48 & 2 & \mathrm{M} & \text { garden } \\ 78 & 2 & \mathrm{M} & \text { garden } \\ 42 & 2 & \mathrm{~F} & \text { garden } \\ 36 & 2 & \mathrm{M} & \text { garden } \\ 48 & 2 & \mathrm{~F} & \text { garden } \\ 48 & 2 & \mathrm{~F} & \text { garden } \\ 48 & 2 & \mathrm{M} & \text { garden } \\ 31 & 2 & \mathrm{~F} & \text { garden } \\ 18 & 1 & \mathrm{~F} & \text { garden } \\ 102 & 2 & \mathrm{M} & \text { garden } \\ 24 & 1 & \mathrm{~F} & \text { app } \\ 36 & 2 & \mathrm{M} & \text { app } \\ 108 & 2 & \mathrm{M} & \text { garden } \\ 30 & 2 & \mathrm{~F} & \text { garden } \\ 48 & 2 & \mathrm{M} & \text { app } \\ 36 & 2 & \mathrm{M} & \text { garden } \\ 9 & 1 & \mathrm{M} & \text { garden } \\ 102 & 2 & \mathrm{~F} & \text { garden } \\ 102 & 2 & \mathrm{M} & \text { garden } \\ 13 & 1 & \mathrm{M} & \text { garden } \\ 24 & 1 & \mathrm{~F} & \text { app } \\ & & & \\ & & \end{array}$

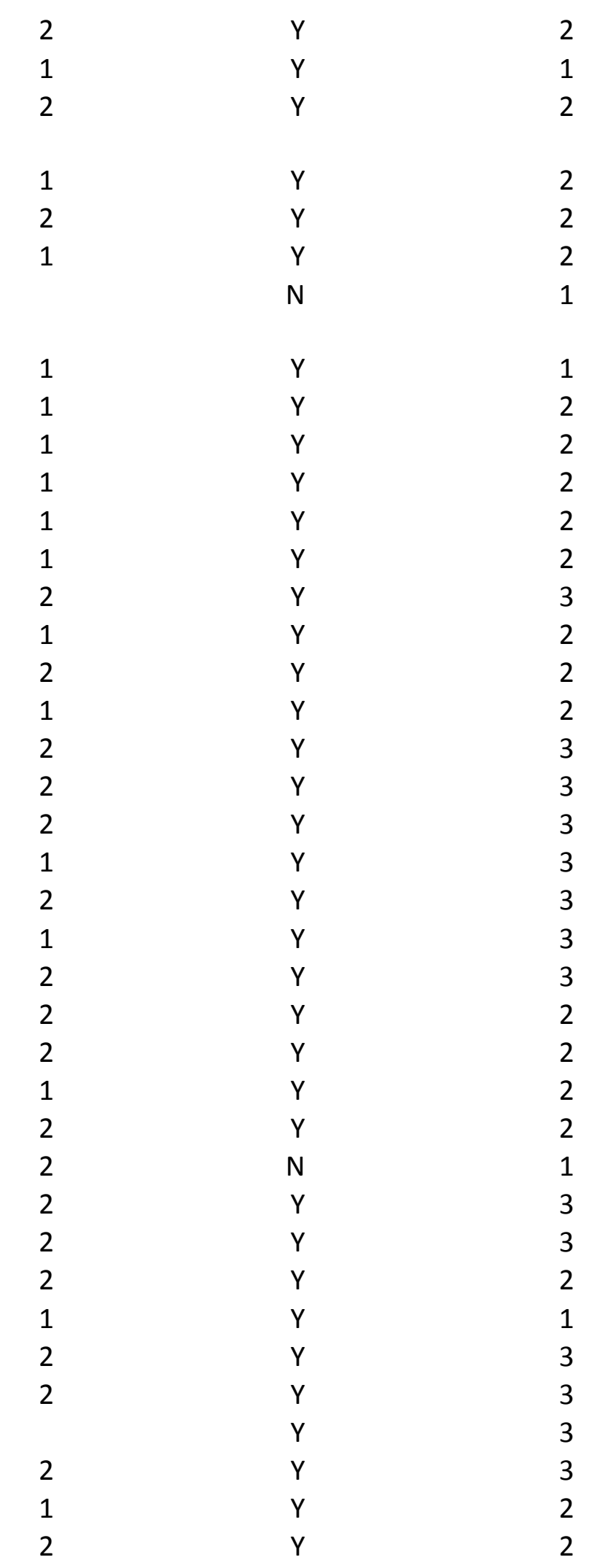


Supplementary Table 2. Means and SEM of the owners' rating obtained from questionnaire.

\begin{tabular}{lcrr}
\hline Owners rating 1-5 & $\mathrm{N}$ & Mean & SEM \\
\hline Happy to see other humans & 84 & 4.0 & 0.12 \\
Happy to see other dogs & 85 & 4.1 & 0.12 \\
Curious/unafraid & 85 & 3.8 & 0.11 \\
Playful & 85 & 4.3 & 0.09 \\
Aggressive towards humans & 85 & 1.3 & 0.07 \\
Aggressive towards other dogs & 85 & 1.6 & 0.10 \\
Cooperative & 85 & 3.9 & 0.09 \\
Stressed & 76 & 2.3 & 0.12
\end{tabular}

